\title{
Predicting impact of a biocontrol agent: integrating distribution modeling with climate-dependent vital rates
}

\author{
Benno Augustinus, ${ }^{1,2}$ Yan Sun, ${ }^{2,3}$ Carine Beuchat, ${ }^{2}$ Urs Schaffner, ${ }^{1}$ and Heinz Müller-Schärer ${ }^{2}$ \\ ${ }^{1}$ CABI, Delémont 2800 Switzerland \\ ${ }^{2}$ Department of Biology, University of Fribourg, Fribourg 1700 Switzerland
}

Citation: Augustinus, B., Y. Sun, C. Beuchat, U. Schaffner, and H. Müller-Schärer. 2020. Predicting impact of a biocontrol agent: integrating distribution modeling with climate-dependent vital rates. Ecological Applications 30(1):e02003. 10.1002/eap.2003

Abstract. Species distribution models can predict the suitable climatic range of a potential biological control agent (BCA), but they provide little information on the BCA's potential impact. To predict high population buildup, a prerequisite of biocontrol impact, studies are needed that assess the effect of environmental factors on vital rates of a BCA across the environmental gradient of the BCA's suitable habitats, especially for the region where the BCA is considered for field release. We extended a published species distribution model with climatedependent vital rates of Ophraella communa, a recently and accidentally introduced potential BCA of common ragweed, Ambrosia artemisiifolia in Europe. In field and laboratory experiments, we collected data on climate-dependent parameters assumed to be the most relevant for the population buildup of $O$. communa, i.e., temperature driving the number of generations per year and relative humidity $(\mathrm{RH})$ determining egg hatching success. We found that $O$. communa concluded one generation in 334 cumulative degree days, and that egg hatching success strongly decreased from $>80 \%$ to $<20 \%$ when $\mathrm{RH}$ drops from $55 \%$ to $45 \%$ during the day. We used these values to spatially explicitly project population densities across the European range suitable for both $A$. artemisiifolia and the beetle and found that the present distribution of the beetle in Europe is within the range with the highest projected population growth. The highest population density of $O$. communa was predicted for northern Italy and parts of western Russia and western Georgia. Field observations of high impact on A. artemisiifolia with records of $80 \%$ aerial pollen reduction in the Milano area since the establishment of $O$. communa are in line with these predictions. The relative importance of temperature and $\mathrm{RH}$ on the population density of $O$. communa varies considerably across its suitable range in Europe. We propose that the combined statistical and mechanistic approach outlined in this paper helps to more accurately predict the potential impact of a weed BCA than a species distribution model alone. Identifying the factors limiting the population buildup of a BCA across the suitable range allows implementation of more targeted release and management strategies to optimize biocontrol efficacy.

Key words: Ambrosia artemisiifolia; bioclimatic range; biocontrol insect; biological invasions; demography; Ophraella communa; range prediction; relative humidity; temperature; weed biocontrol.

\section{INTRODUCTION}

Biological invasions by alien plant species can result in devastating impacts on the invaded ecosystems (Vilà et al. 2011). Accordingly, sustainable management of invasive alien plant species is considered one of the biggest challenges conservation biologists will face in the next decades (Kettenring and Adams 2011). Classical biological control of weeds, i.e., the use of specialist natural enemies from the native range to reduce densities of invasive alien plant species below an economic and ecological threshold, is considered as one of the most

Manuscript received 21 January 2019; revised 28 June 2019; accepted 30 July 2019. Corresponding Editor: Beth Gardner.

${ }^{3}$ Corresponding Author. E-mail: yansun.ecology@gmail.com suitable management options against invasive alien plant species, owing to its effectiveness and relatively high environmental safety (Müller-Schärer and Schaffner 2008, Winston et al. 2014). Predicting the impact of BCAs on the target plant populations remains, however, a challenge in weed biological control (Heimpel and Cock 2018, Paynter et al. 2018, Schwarzländer et al. 2018). Insect population growth is highly dependent on weather, which makes climate suitability an important part of the selection process of weed BCAs (Zalucki and Van Klinken 2006, Robertson et al. 2008). So far, most attention has been given to habitat suitability of a potential biological control candidate (Hoelmer and Kirk 2005, Mukherjee et al. 2011, Sun et al. 2017, 2018). Gassmann (1996), however, argued that the crucial attribute for successful biological control is high population 
buildup of the BCA, as only high densities of the herbivore insect population are expected to result in significant impact on the populations of the target weed (Myers and Sarfraz 2017, Rand et al. 2017, McEvoy 2018). This is supported by the fact that successful biological control of invasive alien plant species is usually linked to population outbreaks of the natural enemies, during which they may reach densities several orders higher than known from their native range (Gassmann 1996, Müller-Schärer and Schaffner 2008). A better understanding of the factors affecting the population dynamics of weed BCAs will thus be key for improving the prediction of their potential impact across the area invaded by the target plant.

Temperature and relative humidity $(\mathrm{RH})$ are generally considered to be the most important climatic factors affecting the population buildup of insects (Odum 1983). Temperature is an essential climatic factor driving insect population densities and is thus used for pest predictive modeling in the agricultural context (Venette 2015, Johnson et al. 2016, Magarey and Isard 2017, Blum et al. 2018). Besides temperature, $\mathrm{RH}$ is also known to strongly influence insect demography, with low RH often resulting in reduced survival or female fitness (Zhou et al. 2010a, Holmes et al. 2012, Wigglesworth 2012). Insect eggs may be particularly sensitive to low RH (Sabelis 1985, Schausberger 1998) as they are immobile and have a large relative surface area, which makes them prone to desiccation (Krysan 1976, Wigglesworth 2012). Numerous studies have shown that low RH negatively affects egg hatching rate of insects from a wide range of taxa (e.g., Sabelis 1985, Chaudry and Alikhan 1990, Bethke and Redak 1996, Byrne et al. 2002, Simelane 2007, Lu and Wu 2011). Within the physiological limits, temperature affects insect population density primarily via developmental time, which may prevent a species to complete its life-cycle or reduce the number of generations in multivoltine species (Milbrath et al. 2014, El Iraqui and Hmimina 2016). In contrast, RH is likely to influence population density by affecting the numbers that develop per generation. For example, Byrne et al. (2002) concluded that the reason for the poor establishment and variable impact of a chrysomelid BCA, Gratiana spadicea Klug, in the introduced range was more likely drought stress than temperature, since RH dropped below the calculated lethal humidity for eggs each month of the year.

The accuracy of population density estimation depends on detailed and long-term systematic monitoring, which requires considerable efforts (Zeng et al. 2015). As an easier and quicker method, species distribution models (SDMs) have been proposed to predict also population densities (Oliver et al. 2012), since SDMs reflect the extent to which local environments meet the niche requirements of the species and thus a species' overall performance (Thuiller et al. 2014). However, the relationship between suitability predictions and population densities often showed uncertainty and contradicting results (Thuiller et al. 2014). Oliver et al. (2012) found a significant positive relationship between habitat suitability and population density for both butterflies and birds, while Csergő et al. (2017) showed that the population growth rate of 34 plant species was not correlated with climate suitability.

Keith et al. (2008) and Gallien et al. (2010) suggested combining statistical and mechanistic models as a twostep approach to make reliable and robust predictions. Following this, we start with published SDMs and explicitly incorporate the environmentally (temperature and $\mathrm{RH}$ ) dependent vital rates (developmental time and hatching success) of a BCA that we experimentally assessed to improve the prediction of the BCA's population density, and ultimately impact within the eco-climatically suitable area. We deliberately kept the mechanistic part simple to provide a quick method to increase the meaningfulness of an SDM. This work is based on the premise that consideration of the effects of temperature and $\mathrm{RH}$ on the population buildup of a BCA in areas suitable for both the target weed and the herbivore allows us to make testable and hopefully more accurate predictions regarding the impact of the BCA in the introduced range than estimates based on SDMs only.

We explored the above mentioned effects with the invasive alien plant Ambrosia artemisiifolia L. (Asteraceae), or common ragweed, and one of its potential BCAs, the North American leaf beetle Ophraella communa LeSage (Coleoptera: Chrysomelidae), which was accidentally introduced and first reported in Europe in 2013 (Müller-Schärer et al. 2014). Ambrosia artemisiifolia has particularly raised awareness for invasive alien plant species in Europe (Kettunen et al. 2009). The main issue with $A$. artemisiifolia is its production of a large number of highly allergenic pollen, resulting in huge health costs through decreased quality of life and productivity of the sensitized population (Burbach et al. 2009, Smith et al. 2013, Mouttet et al. 2018, MüllerSchärer et al. 2018). Furthermore, it is a major agricultural weed, especially in spring-sown crops (Burbach et al. 2009, Smith et al. 2013, Müller-Schärer et al. 2018).

Classical biological control has been successfully applied against $A$. artemisiifolia in China, using the accidentally introduced $O$. communa and the deliberately released stem-galling moth Epiblema strenuana Walker (Zhou et al. 2014). Ophraella communa can reach up to six or seven generations per year in southern China (Zhou et al. 2014) and four or five generations per year in Japan (Yamanaka et al. 2007). The difference is likely due to temperature differences along the latitudinal gradient. In Europe, O. communa starts laying eggs on $A$. artemisiifolia as soon as the first seedlings emerge in early April, indicating that temperature might be a main driver for voltinism in this invaded range. Under laboratory conditions, female $O$. communa enter reproductive diapause under short-day conditions (12 h daylight) and 
at a temperature of $20^{\circ} \mathrm{C}$ (Zhu et al. 2012). Zhou et al. (2010a) showed that a decrease in constant RH from $90 \%$ to $60 \%$ reduced the survival rate of $O$. communa eggs by approximately $30 \%$, while other life stages were less affected (9\% lower larval survival and $2 \%$ lower pupal survival at $60 \% \mathrm{RH}$ compared to $90 \% \mathrm{RH}$ ). In Europe, some areas invaded by $A$. artemisiifolia have $\mathrm{RH}$ values that are considerably lower than those studied by Zhou et al. (2010a), e.g., $<30 \%$ during the daytime in central Hungary. Hence, Europe urgently needs better prediction on the relative importance of temperature and $\mathrm{RH}$ on the population buildup of $O$. communa.

Here, we asked (1) how does temperature affect the development rate of $O$. communa and thus the number of generations per year before the observed initiation of the reproductive diapause in the suitable area in Europe, (2) how does RH affect the egg hatching success of $O$. communa and thus the population buildup within and across generations, (3) what spatially explicit variation in abundances do we expect for $O$. communa, and (4) what is the spatially explicit relative contribution of temperature and $\mathrm{RH}$ to population densities of $O$. communa in the environmentally suitable area in Europe? The overall objective of our two-step approach was to improve with limited additional resources the predictiveness of the pre-release impact assessment for weed BCAs and to identify the specific factors limiting their population buildup, which would allow a more targeted release and management strategy.

\section{Material ANd Methods}

\section{Study species}

Ambrosia artemisiifolia is a North American Asteracean that has invaded areas outside its native range in all continents except Antarctica. In Europe, the annual plant has been considered a weed since the early 1920 s (Csontos et al. 2010). It is invasive in more than 30 countries (Essl et al. 2015) and has reached the status of a flagship invader because of its impact on human health (Sheppard et al. 2006). Up to date, O. communa has been found in Europe predominantly in and close to the Po plain (Augustinus et al. 2015, Lommen et al. 2017), which is a relatively warm and moist area compared to other parts of Europe invaded by A. artemisiifolia (Chapman et al. 2017, Sun et al. 2017). In 2017, O. communa has also been recorded from Slovenia and Croatia (M. Cristofaro, personal observations). Ophraella communa overwinters as adults. In northern Italy, the leaf beetle reaches three to four generations and females were observed to lay eggs from April to August (B. Augustinus and S. T. Lommen, unpublished data). The cessation of oviposition in northern Italy in early September, when day length is approximately $13 \mathrm{~h}$ and average temperature starts dropping below $20^{\circ} \mathrm{C}$, is in line with the experimental studies on the initiation of reproductive diapause in O. communa (Zhu et al. 2012).
Both adults and larvae feed on the green parts of $A$. artemisiifolia plants, which can result in defoliation rates of up to $100 \%$ before the monoecious plants form flowers, preventing pollen and seed production (MüllerSchärer et al. 2014). In Northern Italy, O. communa has been shown to reduce populations on a local scale (Lommen et al. 2018) and, since the arrival of the beetle, airborne $A$. artemisiifolia pollen counts have dropped by $80 \%$, which cannot be explained by meteorological factors or land use changes (Bonini et al. 2015a,b).

\section{Effect of temperature and relative humidity on vital rates of Ophraella communa}

Effect of temperature on developmental time in the field.-The temperature-dependent developmental time of $O$. communa from egg to adult was experimentally assessed at five sites along an altitudinal gradient of $1,100 \mathrm{~m}$ in the Southern Alps, approximately $50 \mathrm{~km}$ north of the Milan area, in the summer of 2016. We followed two cohorts of egg batches (one starting end of June, one starting early August). Potted Ambrosia artemisiifolia plants with freshly laid eggs were individually caged and brought out to the field sites, which we visited weekly to count the number of eggs (hatched or unhatched), pupae, and adults (see Mouttet et al. [2018] for further details). Temperature-dependent pre-oviposition time of $O$. communa was assessed in an experiment in July 2016 at the same sites as described before. Ten newly emerged females were released together with 10 males in a $1 \times 2 \times 1 \mathrm{~m}$ cage with $12 \mathrm{~A}$. artemisiifolia plants, in two cages per site. We recorded the first date of egg deposition.

To assess the temperature conditions required for a complete generation, we measured temperature and relative humidity data locally in 5-min intervals inside and outside of the cages with climate data loggers, (Elektronik AG, Leer, Germany). In addition, we collected weather data from a local weather station (Arconate, of the Servizio Meteorologico Regionale Lombardia), which is $\sim 7.5 \mathrm{~km}$ away from the lowest experimental site. The locally collected weather data were considerably different from the weather station data, with more extreme values (higher temperature, lower $\mathrm{RH}$ ) during the warmest times of sunny days. For the analysis and projection of our climate-dependent data, we chose to use the weather station data, since the available gridded climate data are based on weather station data, rather than on land surface or leaf surface temperatures and RH. We estimated the temperatures for the different sites by reducing the temperatures of the weather station by $0.65^{\circ} \mathrm{C}$ per $100 \mathrm{~m}$ altitudinal gain (ICAO 1993), which is well in line with the temperature attenuation per $100 \mathrm{~m}$ calculated from the measures taken with the climate data loggers $\left(0.69^{\circ} \mathrm{C}\right)$.

We estimated the mean generation time by calculating the mean cumulative degree days (CDD) for every replicate by counting the average number of days until adult emergence and added the CDD for the mean 
pre-oviposition period to it. CDD were calculated using the single sine wave method (Roltsch et al. 1999), with $13.34^{\circ} \mathrm{C}$ as the minimum development threshold temperature for all immature stages (Zhou et al. 2010b). To calculate the standard error (SE) of the CDD, we first estimated SEs for the developmental period from egg to adult and for the pre-oviposition period using 1,000 bootstrap replicates, respectively. As we found no reports of a relationship between the duration of the two periods of $O$. communa development, we considered them as independent and thus used the sum of the two SEs to represent the $\mathrm{SE}$ of the $\mathrm{CDD}$ over one generation.

Effect of relative humidity on the egg hatching rate.-The effect of $\mathrm{RH}$ on egg hatching rate, defined here as the percentage of fertilized eggs that successfully hatch, was determined in a growth-chamber experiment at the University of Fribourg. Ambrosia artemisiifolia plants were grown from seeds collected in Busto Arsizio, Italy, in 2015 and 2016. Seeds were germinated in closed Petri dishes on moist filter paper in a climate chamber at $18^{\circ}-$ $26^{\circ} \mathrm{C}$, with a photoperiod of $16: 8$ (light: dark). After germination, seedlings were transplanted in standard potting soil and kept in the biosecurity greenhouse at University of Fribourg, with a light regime of 16:8 (light: dark) and temperatures of $13^{\circ}-29^{\circ} \mathrm{C}$. Ophraella communa were collected in Grugliasco, northern Italy, in September 2016 and reared in the quarantine facility of the Biology Department, University of Fribourg, at $26^{\circ} \mathrm{C}$ during the day and $17^{\circ} \mathrm{C}$ during the night, at $60 \%$ $\mathrm{RH}$ and a daylight regime of 16:8 (light: dark).

Three days before treatments were set up, $12 \mathrm{~A}$. artemisiifolia plants in the vegetative state (8-12 leaves) were exposed to $O$. communa adults (20 females and 20 males) of various ages in a cage and daily inspected for newly laid egg batches. To prevent insects from crawling into the soil, we covered the top of the pot with a filter paper disc before exposure to O. communa adults. Small leaves were removed to ensure that the egg-infested leaves were suitable for the experiment. Leaves with at least one egg batch consisting of more than 10 eggs were cut off the plant at the leaf petiole with a sharp scalpel blade and randomly assigned to a treatment. Leaves with egg batches with $<10$ eggs were discarded.

Of 50-mL Falcon tubes (Fisher Scientific, Hampton, New Hampshire, USA) were filled with water and sealed with Parafilm (Bernis Company, Neenah, Wisconsin, USA). The Parafilm was punctured with a needle and the petiole of a leaf with eggs was inserted into the tube, sealing the hole. The tubes with leaves were put in a holder for $50-\mathrm{mL}$ tubes. The holders stood on a plastic plate, of which the borders were lined with double-sided sticky tape to prevent larvae from crawling away. The tubes were placed in two KB 8400 FL incubators (Termaks, Bergen, Norway) with programmable humidity, light and temperature functions.

Each RH treatment was conducted with at least 15 replicates. The driest RH treatment was based on the climate data recorded between mid and end of August from a site in the Pannonian plain (data from the weather station at Hodmezovasarhely, Hungary), one of the warmest and driest regions of the A. artemisiifolia distribution in Europe. The incubators were programmed in order to match the hourly variation in $\mathrm{RH}$ and temperature under natural conditions as closely as possible (Appendix S1: Figs. S1 and S2). The additional RH treatments were set at the RH of the driest treatment plus 7\%, $14 \%, 17 \%, 20 \%$, and 24\%, respectively (Appendix S1: Fig. S3), while temperature and light regimes were kept identical among treatments. The light regime was set to mimic the daytime in Hungary in late July (14:10 light: dark). We measured egg hatching rate across the six $\mathrm{RH}$ treatments, with the treatments randomly assigned to one of the two incubators. Each RH treatment lasted $12 \mathrm{~d}$. Data from one run had to be omitted from the analysis because of technical problems with the incubator.

After assigning the egg batches to a treatment, they were inspected daily and their status (alive, dead, hatched, and unfertilized) recorded. We scored eggs as "dead" if they turned black, as "hatched" when a hole was found in the egg and the egg was empty, and as "unfertilized" when the eggs became flat without turning black. Hatching success was calculated as the percentage of hatched eggs relative to fertilized eggs (sum of hatched and dead eggs). The experiments ran from March through July 2017.

For validation of our treatments, temperature and $\mathrm{RH}$ were measured with loggers (ELV TDF 128) in each incubator every 5 minutes. Due to technical limitations of the incubators, we did not get an exactly evenly spaced $\mathrm{RH}$ range. To account for this variation, we averaged all measured RH values measured from $14: 30$ to $15: 30$ by the data loggers in the middle of the incubator. We fitted generalized linear mixed models (GLMM) using the lmer function of the lme4 package (Bates et al. 2015) using the $\mathrm{RH}$ treatments as a fixed factor and incubator and date of start of the replicate as random factors. As response variables we tested hatching time (number of days from egg deposition until first hatching egg of batch), hatching interval (number of days from first to last egg hatching within a given batch) and egg batch size using a Poisson distribution, and hatching success using a binomial distribution. Gompertz models have been used to describe the effect of environmental factors on egg hatching success (Omkar and Mishra 2010, Quiroz et al. 2015). We fitted a three-parameter modified Gompertz model to the experimental $\mathrm{RH}$ data to determine the hatching success with the formula

$$
\mathrm{HS}_{i}=f_{h}\left(\mathrm{RH}_{i}\right)=(1-\alpha) \times e^{\left(-\beta \times e^{\left(-\gamma \times \mathrm{RH}_{i}\right)}\right)}+\alpha
$$

where $i$ refers to the selected month $(i=4-8$; AprilAugust), $\alpha$ is the baseline of hatching success that is assumed to have a maximum value of $1, \beta$ denotes the displacement across the $x$-axis (RH of the month $i$ ) and 
$\gamma$ is the rate of increase (Gompertz 1825). The method of least squares was used to fit the Gompertz model and optimal-fit parameter estimates were obtained using the Nelder Mead algorithm in optim, a general purpose optimization function of stats package (R Core Team 2018). To estimate the confidence intervals of the three parameters of the Gompertz model, 1,000 bootstrap estimates were performed using the boot function of the boot package (Canty and Ripley 2017). The Akaike Information Criterion (AIC) was used to select the most appropriate model. We found that the Gompertz model results in a lower AIC than a logistic function, with 170.74 and 884.71 for Gompertz and logistic model, respectively. We thus chose the Gompertz model for computing hatching success, as lower AIC values indicate more information preserved in the model and thus greater model performance.

\section{Modeling population density}

Number of generations of Ophraella communa. - To estimate the number of generations of $O$. communa across its suitable area in Europe, we used the above obtained average CDD, based on a base temperature $T_{\text {base }}$ of $13.34^{\circ} \mathrm{C}$ (Zhou et al. 2010b) for the period from the egg stage to adult emergence of $O$. соттипа, and added the accordingly calculated CDD for the pre-oviposition period to achieve the CDD for one generation, since earlier results show a highly significant linear relationship between developmental time and temperature (Zhou et al. 2010b). The number of generations $(G)$ was calculated for every month or the whole growing season, using the formula

$$
G_{i}=\frac{\bar{T}_{i} \times \text { days }}{\mathrm{CDD}_{\text {bootstrap }}}
$$

where $i$ refers to the selected month $(i=4-8$; AprilAugust), $\bar{T}_{i}$ is the average temperature of the month $i$, $\mathrm{CDD}_{\text {bootstrap }}$ refers to the 1,000 bootstrap estimates. SE of the generation was therefore calculated based on the above 1,000 bootstrap estimates (Appendix S2: Fig. S1).

Relative humidity estimation and hatching rate of Ophraella communa across the European range.-We used monthly average RH and monthly minimum and maximum temperature derived from CRU CL2.0 data sets (New et al. 2002) at 10-min spatial resolution ( $\sim 20 \mathrm{~km}$ closer to the equator) to estimate the RH in the afternoon of each day, i.e., at 15:00, based on the method proposed by Kriticos et al. (2012). We used the $\mathrm{RH}$ at 15:00, which was the driest hour in the field measurements in the Pannonian plain and in the measurements of the weather station in Hodmezovasarhely, and because it is indicative for the driest 6 hours of the day (B. Augustinus, personal observation). The climatic data are considered from April to August, i.e., the egg-laying period of $O$. communa in Europe. The egg hatching rate was therefore calculated based on the above obtained Gompertz formula and estimated RH (Appendix S2: Figs. S2 and S3).

Abundances of Ophraella communa.-We calculated the potential maximum population density of $O$. communa in Europe using the average climate of the total egg laying period (April-August) and the average climate per month. For this, we assumed no shortage of the host plants and no effects of natural enemies. To consider monthly variation, population density was calculated for every month separately, using the number of overwintering females or females of the previous month, the number of eggs per female, hatching rate and the number of generations per month. The values for August were then used as the final population density (PD) and thus abundance (model I), using the formula

$$
\begin{gathered}
\mathrm{PD}_{i}=G_{i} \times \frac{\mathrm{PD}_{i-1}}{2} \times 25 \times \mathrm{HS}_{i}, \\
\mathrm{PD}_{\bmod 1}=\mathrm{PD}_{8}
\end{gathered}
$$

where $i$ is the selected month ( $i=4-8$; April to August), for the first month of the growth season, April, we considered the number of overwintering females is 1 as a start simulation point. Thus, we assumed that the number of overwintering females was the same across the suitable area in Europe. The average number of eggs laid per female was assumed to be 25 , based on previous studies (Yamazaki et al. 2000, Fukano et al. 2016). The relationship between suitability from SDM (using the data from Sun et al. 2017) and population density of $O$. communa calculated from model I was also evaluated.

To explore the relative importance of the average temperature and RH on the population density of $O$. communa, we modeled the population density based on the average temperature and $\mathrm{RH}$ from April to August (model II), using the formula

$$
\left.\mathrm{PD}_{\bmod 2}=f_{\mathrm{pd}}\left(\overline{T_{a}}, \overline{\mathrm{RH}_{1500}}\right)=\frac{25 \times f_{h}\left(\overline{\mathrm{RH}_{1500}}\right)}{2}\right)_{\overline{T_{a}}}^{G_{1}}
$$

where $f_{\mathrm{pd}}\left(\overline{T_{a v}}, \overline{\mathrm{RH}_{1500}}\right)$ refers to the population density function of average temperature and average $\mathrm{RH}$ at 15:00, $f_{h}\left(\overline{\mathrm{RH}_{1500}}\right)$ is the Gompertz function of average RH for hatching success, and $G_{\overline{T_{a}}}$ is the number of generations calculated based on the average temperature from April to August with $\mathrm{CDD}_{\text {bootstrap. }} \mathrm{SE}$ of the population density $\left(\mathrm{PD}_{\bmod 2}\right)$ is calculated based on the 1,000 bootstrap replicates (Appendix S2: Fig. S4). To test for the agreement between the model I and II, we computed the correlation between the predictions obtained from the two models (see Appendix S2: Figs. S4-S6).

Relative importance of temperature and $R H$ on population density.-The relative importance can be derived from 
Average temperature contributed more than $\mathrm{RH}$ to population density of $O$. communa, when $\mathrm{RH}$ was above $52 \%$ at 15:00, while average RH was a key climatic factor when it was below 48\% at 15:00 (Fig. 4). We found that the best climatic conditions to achieve a high population density of $O$. communa are $23^{\circ}-25^{\circ} \mathrm{C}$ (average temperature, April-August) and 53\%-65\% (average RH, April-August) at 15:00 (Appendix S2: Fig. S8). This information was then used to map the relative importance of the two climatic factors on the population density of $O$. communa within its suitable area in Europe (Fig. 5). Population density of O. communa in the Apennines, north of the Alps, north of the Dinaric Alps, in Romania and along the Black Sea coast of Russia and Georgia is shown to be primarily affected by temperature, while population density south of the Massif Central, south of the Dinaric Alps, in Serbia, western Georgia and a small part of western Russia is predicted to be largely affected by RH (Fig. 5).

\section{Discussion}

Our study reveals that both temperature and $\mathrm{RH}$ affect vital rates of $O$. communa and that adding physiologically-based demographic data to a SDM results in predictions of significant variation in the population density of $O$. communa across the climatically suitable regions in Europe. The currently invaded range by $O$. communa in Northern Italy is predicted to support one of the highest population growth rates in Europe, which is in line with our observation of $80 \%$ pollen reduction in this area (Bonini et al. 2015a,b). Other regions that appear particularly suitable for high population densities are the warm and moist areas in western Georgia and the Krasnodar region. Our findings suggest that both temperature and $\mathrm{RH}$ affect population dynamics, but that the relative importance of these two environmental variables varies across the suitable range.

\section{Impact of temperature and $R H$ on vital rates of O. communa}

In our field experiments, O. communa completed a generation from egg to reproductive adult in $334.04 \pm 11.09 \mathrm{CDD}$, which is similar to the earlier experiments by Zhou et al. (2010b), which suggested it would take 307.20 CDD. The discrepancy in these values could be explained with the nature of the different studies. First, Zhou et al. (2010b) did not include the CDD of the pre-oviposition period. Secondly, we describe the results of field experiments, while the experiments of

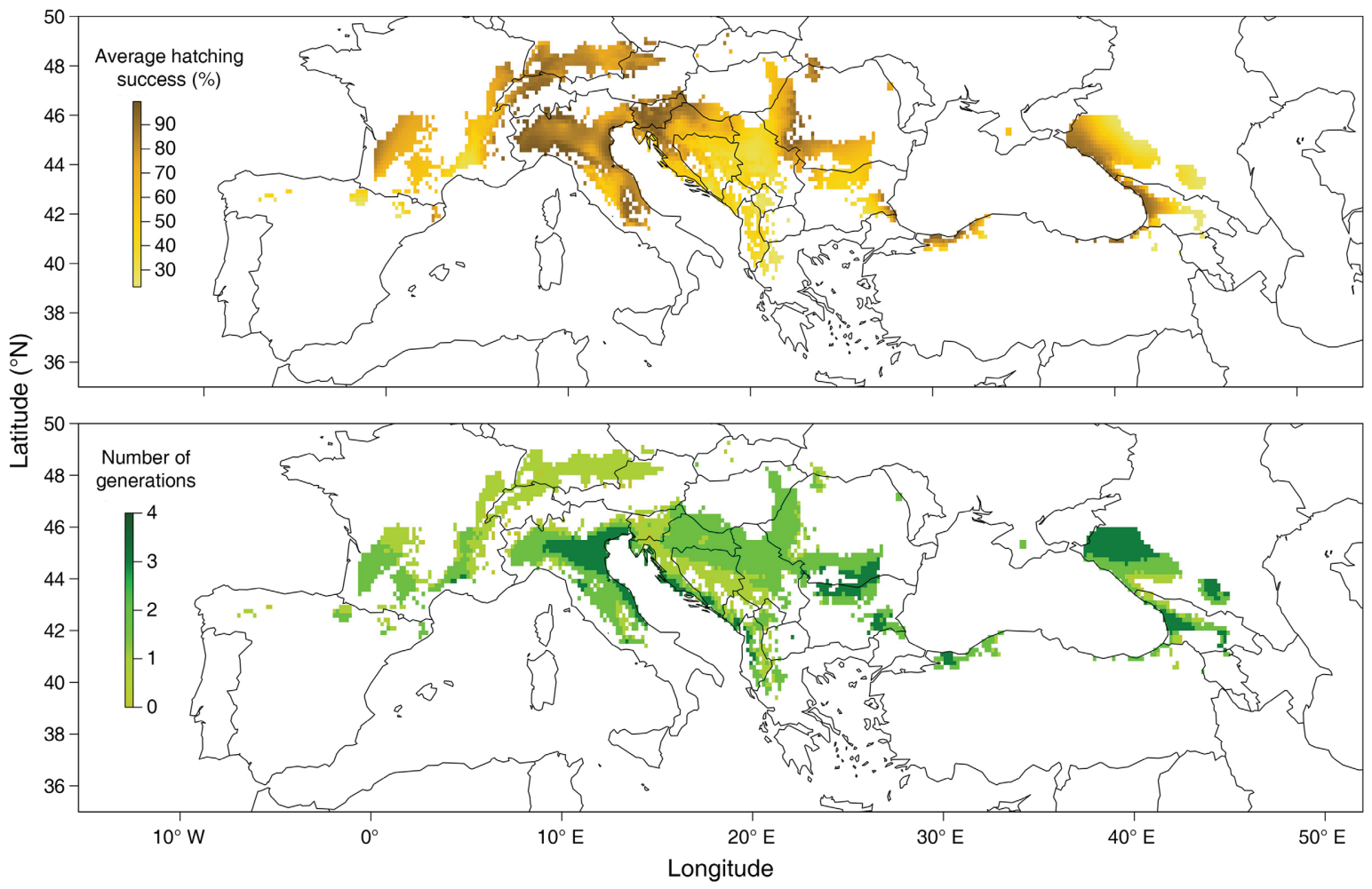

FIG. 2. Average hatching rate of Ophraella communa during the growth period from April to August (top), and number of generations of $O$. communa in August (below) across the European range climatically suitable for both Ambrosia artemisiifolia and O. communa. 


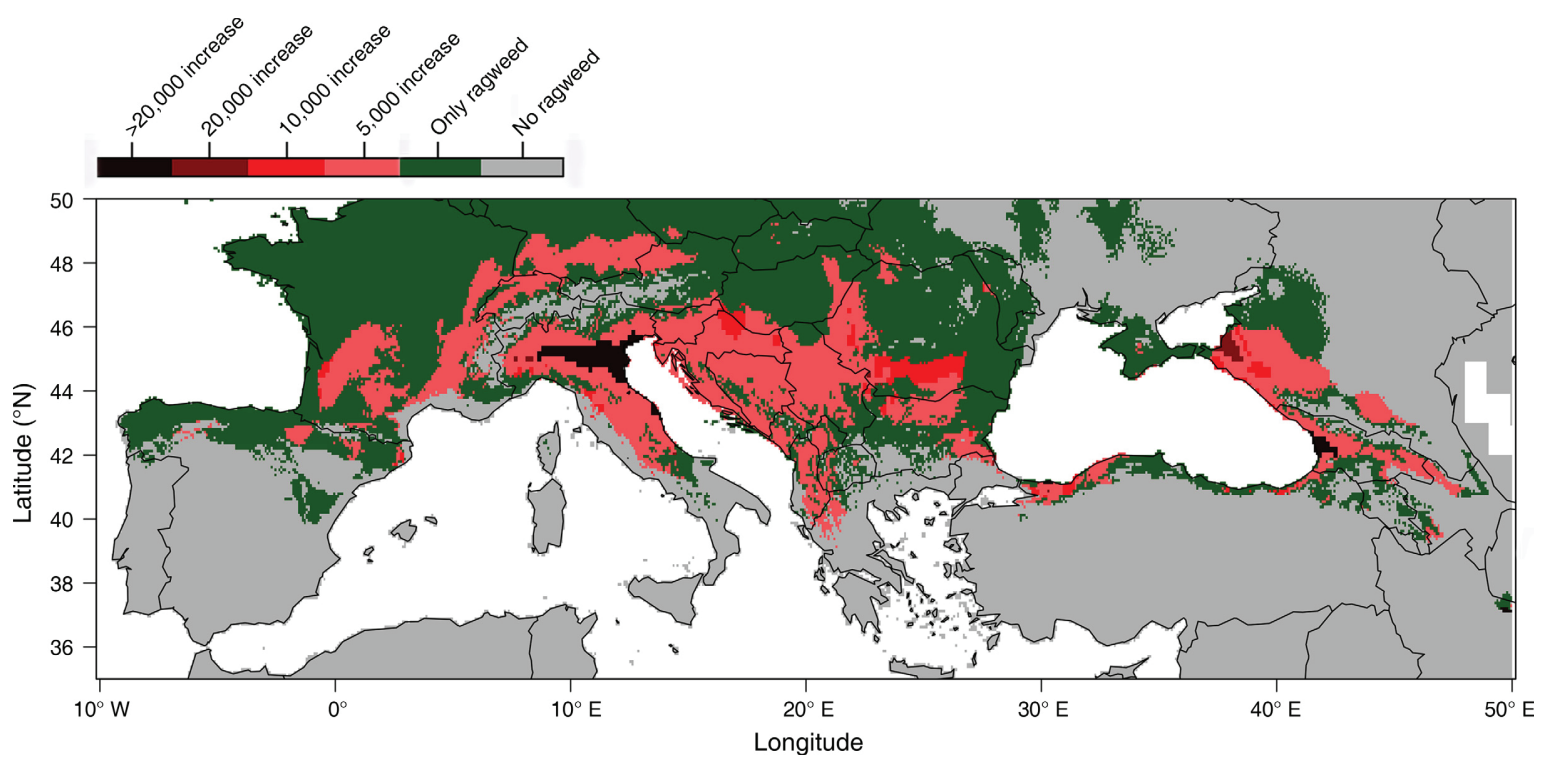

FIG. 3. Population density of Ophraella communa based on average relative humidity and relative temperature from Model II (Eq. 5). Gray color indicates the area not suitable for both A. artemisiifolia and $O$. communa; green color indicates the area suitable for Ambrosia artemisiifolia but not for O. communa; reddish colors indicate the area suitable for both A. artemisiifolia and $O$. communa: the darker the reddish color, the higher the density.

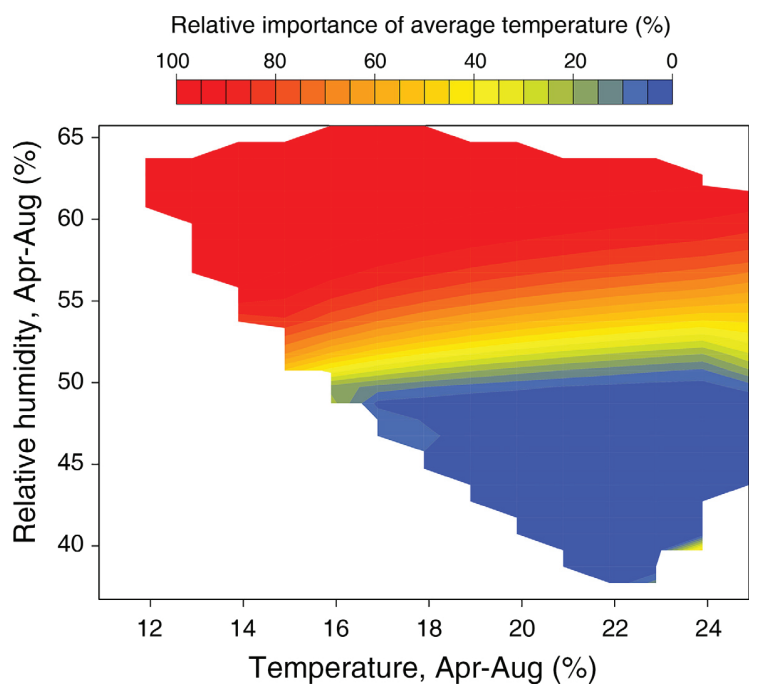

FIG. 4. Heat map of relative importance of temperature vs. relative humidity (given as percentage importance of temperature) across the suitable European area of both Ambrosia artemisiifolia and Ophraella communa. Values are means. Red color represents a higher importance of temperature (AprilAugust) and blue color represents a higher importance of relative humidity (April-August) on the population density of O. communa.

Zhou et al. (2010b) were conducted under constant temperatures in a laboratory environment. In a field experiment with fluctuating temperatures and solar exposure, insects can adjust their body temperatures by their behavior like hiding from the sun or basking (Eigenbrode et al. 2015). The sigmoid form of the fitted curve for the relationship between $\mathrm{RH}$ and egg hatching rate showed a strong decrease when $\mathrm{RH}$ dropped below 55\% during the driest time of the day (see Fig. 1). In laboratory experiments using constant RH levels, Zhou et al. (2010a) found that egg hatching success of $O$. communa was significantly higher at $75 \%$ and $90 \% \mathrm{RH}$, compared to $60 \% \mathrm{RH}$. In the area in Europe that is climatically suitable for $O$. communa, average $\mathrm{RH}$ does not reach such high average values, largely because of a significant drop in $\mathrm{RH}$ during daytime. In order to approximate field conditions, we included daily variation in our treatments. We found a hatching rate of $>85 \%$ at $\mathrm{RH}$ of $65 \%$, which is considerably higher than that found by Zhou et al. (2010a), who report a hatching rate of $55.6 \% \pm 1.6 \%$ at $60 \% \mathrm{RH}$ and $84.5 \% \pm 1.3 \%$ at $75 \%$ RH.

We used weather station data for our estimations since the readily available gridded climate datasets are based on weather station data. The climate data we measured in the field, however, showed more extreme values than the values of nearby weather stations. The shaded data loggers used to obtain these data were placed in between the plants to display the temperature and $\mathrm{RH}$ experienced by the insects. Weather stations follow a protocol that provides standardized measurements of temperatures on a global scale, but they measure air temperature, not foliage or land surface temperatures (Mendelsohn et al. 2007). Using land surface or foliage surface temperatures might improve predictions of the insect's demography, as it did for population models of the olive fruit fly (Bactrocera oleae Rossi) (Blum et al. 2015) and cotton bollworm, Helicoverpa armigera Hübner (Blum et al. 2018). When making predictions 
different environmental contexts; and Buckley (2007) showed how geographic variation in traits and life histories influences lizard population densities.

In summary, we propose that our approach allows a simple projection of the population growth at a given site in the suitable area relative to other sites that the $\mathrm{BCA}$ is able to colonize, of the region that is considered for field release, or relative to a site where we already know the population growth and/or the impact of the BCA. Furthermore, our approach allows us to analyze the relative importance of changes in temperature and $\mathrm{RH}$ affecting demography of the BCA, especially in view of inferring management decisions.

\section{Management implications}

Our study revealed that the projected population growth of $O$. communa in its currently colonized area in northern Italy is among the highest in Europe, together with areas in western Georgia and the Krasnodar region, where $A$. artemisiifolia is also highly invasive (Reznik 2009). The high O. communa densities observed in Northern Italy since its detection in 2013 and the concomitant $80 \%$ reduction in airborne pollen concentrations cannot be explained by meteorological factors (Bonini et al. 2015a,b). Hence, our findings suggest that O. communa will be able to drastically reduce pollen production and related health costs also in western Georgia and the Krasnodar region, provided that the beetle is able to actively colonize these regions. Considering the benefit of $O$. communa in other parts of Europe (Bonini et al. 2015a,b, Mouttet et al. 2018), a risk-assessment of human-assisted dispersal of the beetle in these regions should be considered.

A way to further increase the impact of $O$. communa on A. artemisiifolia in Europe is then to adopt a mass rearing program, as it is currently practiced in China (Zhou et al. 2009). Targeted mass releases of beetles could be envisaged in areas where low $\mathrm{RH}$ during a certain period in spring may slow down the population growth of $O$. communa. For example, parts of southeastern France, which harbor high $A$. artemisiifolia densities and are characterized by relatively dry conditions in April, may be potential target areas for mass releases in May.

In other regions, where $\mathrm{RH}$ is limiting population establishment and/or population density throughout the season, successful biological control of $A$. artemisiifolia may require introducing a different, more drought-resistant strain of $O$. communa, or of a different BCA, which is less susceptible to low RH. An example for such a region is the Pannonian plain in Hungary, where $A$. artemisiifolia is a particularly problematic weed (Kőmíves et al. 2006). For areas predicted to have lower O. communa densities and that are more sensitive to temperature, e.g., North of the Alps, one can test for the possibility to develop a cold-tolerant/resistant strain. Zhou et al. (2013) recently studied the potential of $O$. communa to adapt to cold temperatures to assess the possibility of an expansion toward northern China. Their results indicate that cold hardiness of $O$. communa can be promoted by cold acclimation in the previous generation, and that it might counterbalance reduced survival in the next generation, when insects are tracking their host plants into colder climates.

\section{Conclusions}

We propose combining statistically based SDM with the experimental assessment of climate-dependent vital rates for improving the prediction of the potential population growth of BCAs. Our results on O. communa show that the relative importance of climatic factors affecting population growth greatly differs spatially across the range that is climatically suitable for both the plant invader and its BCA. From a management perspective, we advocate the proposed combined approach as a step forward to improve predicting the impact in weed biological control programs as well as to increase impact by conducting informed management.

\section{ACKNOWLEDGMenTs}

Yan Sun and Benno Augustinus contributed equally to this study. We are grateful to Anne-Marth Tournet for her assistance in laboratory work and Louis-Félix Bersier and Rudolf Rohr for their help in performing robust statistical analyses. The study was funded by the e-COST Action FA1203 "Sustainable management of Ambrosia artemisiifolia in Europe (SMARTER)", the Swiss State Secretariat for Education, Research and Innovation (\#C14.0063 to U. Schaffner and H. MüllerSchärer), the Pool de Recherche of the University of Fribourg (to H. Müller-Schärer and B. Augustinus) and the Novartis Foundation (\#17B083 to H. Müller-Schärer and Y. Sun). Urs Schaffner was supported by CABI with core financial support from its member countries (see http://www.cabi.org/about-cabi/ who-we-work-with/key-donors/).

\section{Literature Cited}

Augustinus, B. A., M. F. Guarino, F. Colombo, S. Citterio, U. Schaffner, H. Müller-Schärer, and R. Gentili. 2015. Nuove Segnalazioni di Ambrosia artemisiifolia e Ophraella communa in Valtellina (Alpi centrali, Lombardia). Natura Bresciana 39:235-238.

Bates, D., M. Maechler, B. Bolker, and S. Walker. 2015. Fitting linear mixed-effects models using lme4. Journal of Statistical Software 67:1-48.

Bethke, J. A., and R. A. Redak. 1996. Temperature and moisture effects on the success of egg hatch in Trirhabda geminata (Coleoptera: Chrysomelidae). Annals of the Entomological Society of America 89:661-666.

Blum, M., I. M. Lensky, P. Rempoulakis, and D. Nestel. 2015. Modeling insect population fluctuations with satellite land surface temperature. Ecological Modelling 311:39-47.

Blum, M., D. Nestel, Y. Cohen, E. Goldshtein, D. Helman, and I. M. Lensky. 2018. Predicting Heliothis (Helicoverpa armigera) pest population dynamics with an age-structured insect population model driven by satellite data. Ecological Modelling 369:1-12.

Bonini, M., B. Šikoparija, M. Prentović, G. Cislaghi, P. Colombo, C. Testoni, L. Grewling, S. T. Lommen, H. MüllerSchärer, and M. Smith. 2015a. Is the recent decrease in 
airborne Ambrosia pollen in the Milan area due to the accidental introduction of the ragweed leaf beetle Ophraella communa? Aerobiologia 31:499-513.

Bonini, M., B. Šikoparija, M. Prentović, G. Cislaghi, P. Colombo, C. Testoni, Ł. Grewling, S. T. Lommen, H. MüllerSchärer, and M. Smith. 2015b. A follow-up study examining airborne Ambrosia pollen in the Milan area in 2014 in relation to the accidental introduction of the ragweed leaf beetle Ophraella communa. Aerobiologia 32:371-374.

Buckley, L. B. 2007. Linking traits to energetics and population dynamics to predict lizard ranges in changing environments. American Naturalist 171:E1-E19.

Burbach, G., L. Heinzerling, C. Röhnelt, K. C. Bergmann, H. Behrendt, and T. Zuberbier. 2009. Ragweed sensitization in Europe-GA2LEN study suggests increasing prevalence. Allergy 64:664-665.

Byrne, M. J., S. Currin, and M. P. Hill. 2002. The influence of climate on the establishment and success of the biocontrol agent Gratiana spadicea, released on Solanum sisymbriifolium in South Africa. Biological Control 24:128-134.

Canty, A., and B. Ripley. 2017. boot: Bootstrap R (S-Plus) functions. R package version 1.3-20. https://cran.r-project. org/web/packages/boot/index.html

Chapman, D. S., R. Scalone, E. Štefanić, and J. M. Bullock. 2017. Mechanistic species distribution modeling reveals a niche shift during invasion. Ecology 98:1671-1680.

Chaudry, Z., and M. Alikhan. 1990. Effects of temperature and relative humidity on the development and the fecundity of the red pumpkin beetle Aulacophora foveicollis Lucos (Chrysomelidae Coleoptera). Indian Journal of Entomology 52:274-278.

Csergő, A. M., R. Salguero-Gómez, O. Broennimann, S. R. Coutts, A. Guisan, A. L. Angert, E. Welk, I. Stott, B. J. Enquist, and B. McGill. 2017. Less favourable climates constrain demographic strategies in plants. Ecology Letters 20:969-980.

Csontos, P., M. Vitalos, Z. Barina, and L. Kiss. 2010. Early distribution and spread of Ambrosia artemisiifolia in Central and Eastern Europe. Botanica Helvetica 120:75-78.

Ehrlén, J., and W. F. Morris. 2015. Predicting changes in the distribution and abundance of species under environmental change. Ecology Letters 18:303-314.

Eigenbrode, S. D., T. S. Davis, and D. W. Crowder. 2015. Climate change and biological control in agricultural systems: principles and examples from North America. Pages 119-135 in C. Björkman, and P. Niemelä, editors. Climate change and insect pests. CABI, Wallingford, UK.

El Iraqui, S., and M. Hmimina. 2016. Impact of temperatures on the voltinism of Cydia pomonella (Lepidoptera: Tortricidae). Annals of the Entomological Society of America 109:698-704.

Elith, J., and J. R. Leathwick. 2009. Species distribution models: ecological explanation and prediction across space and time. Annual Review of Ecology, Evolution, and Systematics 40:677-697.

Essl, F., K. Biró, D. Brandes, O. Broennimann, J. M. Bullock, D. S. Chapman, B. Chauvel, S. Dullinger, B. Fumanal, and A. Guisan. 2015. Biological flora of the British Isles: Ambrosia artemisiifolia. Journal of Ecology 103:1069-1098.

Fukano, Y., H. Doi, C. Thomas, M. Takata, S. Koyama, and T. Satoh. 2016. Contemporary evolution of host plant range expansion in an introduced herbivorous beetle Ophraella communa. Journal of Evolutionary Biology 29:757-765.

Gallien, L., T. Münkemüller, C. H. Albert, I. Boulangeat, and W. Thuiller. 2010. Predicting potential distributions of invasive species: Where to go from here? Diversity and Distributions 16:331-342.
Gassmann, A. 1996. Classical biological control of weeds with insects: a case for emphasizing agent demography. Pages 171-175 in V.C. Moran and J. H. Hoffmann, editors. Proceedings of the IX international symposium on biological control of weeds. University of Cape Town, Stellenbosch, South Africa.

Gompertz, B. 1825. XXIV. On the nature of the function expressive of the law of human mortality, and on a new mode of determining the value of life contingencies. In a letter to Francis Baily, Esq. FRS \& c. Philosophical Transactions of the Royal Society of London 115:513-583.

Heimpel, G. E., and M. J. W. Cock. 2018. Shifting paradigms in the history of classical biological control. BioControl 63:2737.

Hoelmer, K., and A. Kirk. 2005. Selecting arthropod biological control agents against arthropod pests: Can the science be improved to decrease the risk of releasing ineffective agents? Biological Control 34:255-264.

Holmes, L., S. Vanlaerhoven, and J. Tomberlin. 2012. Relative humidity effects on the life history of Hermetia illucens (Diptera: Stratiomyidae). Environmental Entomology 41:971978.

ICAO. 1993. Manual of the ICAO standard atmosphere: extended to 80 kilometres (262 500 Feet). International Civil Aviation Organization. Montreal, Canada.

Johnson, C. A., R. M. Coutinho, E. Berlin, K. E. Dolphin, J. Heyer, B. Kim, A. Leung, J. L. Sabellon, and P. Amarasekare. 2016. Effects of temperature and resource variation on insect population dynamics: the bordered plant bug as a case study. Functional Ecology 30:1122-1131.

Kearney, M., and W. Porter. 2009. Mechanistic niche modelling: combining physiological and spatial data to predict species' ranges. Ecology Letters 12:334-350.

Keith, D. A., H. R. Akçakaya, W. Thuiller, G. F. Midgley, R. G. Pearson, S. J. Phillips, H. M. Regan, M. B. Araújo, and T. G. Rebelo. 2008. Predicting extinction risks under climate change: coupling stochastic population models with dynamic bioclimatic habitat models. Biology Letters 4:560-563.

Kettenring, K. M., and C. R. Adams. 2011. Lessons learned from invasive plant control experiments: a systematic review and meta-analysis. Journal of Applied Ecology 48:970-979.

Kettunen, M., P. Genovesi, S. Gollasch, S. Pagad, U. Starfinger, P. ten Brink, and C. Shine. 2009. Technical support to EU strategy on invasive alien species (IAS). Institute for European Environmental Policy (IEEP), Brussels, Belgium.

Kömíves, T, et al. 2006. New strategy of the integrated protection against common ragweed (Ambrosia artemisiifolia L.). Magyar Gyomkutatás és Technológia 7:5-49.

Kriticos, D. J., B. L. Webber, A. Leriche, N. Ota, I. Macadam, J. Bathols, and J. K. Scott. 2012. CliMond: global high-resolution historical and future scenario climate surfaces for bioclimatic modelling. Methods in Ecology and Evolution 3:53-64.

Krysan, J. L. 1976. Moisture relationships of the egg of the southern corn rootworm, Diabrotica undecimpunctata howardi (Coleoptera: Chrysomelidae). Entomologia Experimentalis et Applicata 20:154-162.

Lommen, S. T., E. F. Jolidon, Y. Sun, J. I. B. Eduardo, and H. Müller-Schärer. 2017. An early suitability assessment of two exotic Ophraella species (Coleoptera: Chrysomelidae) for biological control of invasive ragweed in Europe. European Journal of Entomology 114:160-169.

Lommen, S. T., C. A. Hallmann, E. Jongejans, B. Chauvel, M. Leitsch-Vitalos, A. Aleksanyan, P. Tóth, C. Preda, M. Śćepanović, and H. Onen. 2018. Explaining variability in the production of seed and allergenic pollen by invasive Ambrosia artemisiifolia across Europe. Biological Invasions 20:14751491. 
Lu, Y., and K. Wu. 2011. Effect of relative humidity on population growth of Apolygus lucorum (Heteroptera: Miridae). Applied Entomology and Zoology 46:421-427.

Magarey, R. D., and S. A. Isard. 2017. A troubleshooting guide for mechanistic plant pest forecast models. Journal of Integrated Pest Management 8:3-3.

McEvoy, P. B. 2018. Theoretical contributions to biological control success. BioControl 63:1-17.

Mendelsohn, R., P. Kurukulasuriya, A. Basist, F. Kogan, and C. Williams. 2007. Climate analysis with satellite versus weather station data. Climatic Change 81:71-83.

Milbrath, L. R., C. J. Deloach, and J. L. Tracy. 2014. Overwintering survival, phenology, voltinism, and reproduction among different populations of the leaf beetle Diorhabda elongata (Coleoptera: Chrysomelidae). Environmental Entomology 36:1356-1364.

Mouttet, R., B. Augustinus, M. Bonini, B. Chauvel, N. Desneux, E. Gachet, T. Le Bourgeois, H. Müller-Schärer, M. Thibaudon, and U. Schaffner. 2018. Estimating economic benefits of biological control of Ambrosia artemisiifolia by Ophraella communa in southeastern France. Basic and Applied Ecology 33:14-24.

Mukherjee, A., M. C. Christman, W. A. Overholt, and J. P. Cuda. 2011. Prioritizing areas in the native range of hygrophila for surveys to collect biological control agents. Biological Control 56:254-262.

Müller-Schärer, H., and U. Schaffner. 2008. Classical biological control: exploiting enemy escape to manage plant invasions. Biological Invasions 10:859-874.

Müller-Schärer, H., S. T. Lommen, M. Rossinelli, M. Bonini, M. Boriani, G. Bosio, and U. Schaffner. 2014. Ophraella communa, the ragweed leaf beetle, has successfully landed in Europe: Fortunate coincidence or threat? Weed Research 54:109119.

Müller-Schärer, H., et al. 2018. Cross-fertilizing weed science and plant invasion science to improve efficient management: a European challenge. Basic and Applied Ecology 33:1-13.

Myers, J. H., and R. M. Sarfraz. 2017. Impacts of insect herbivores on plant populations. Annual Review of Entomology 62:207-230.

New, M., D. Lister, M. Hulme, and I. Makin. 2002. A highresolution data set of surface climate over global land areas. Climate Research 21:1-25.

Norhisham, A. R., F. Abood, M. Rita, and K. R. Hakeem. 2013. Effect of humidity on egg hatchability and reproductive biology of the bamboo borer (Dinoderus minutus Fabricius). SpringerPlus 2:9.

Odum, E. 1983. Basic ecology. Holt-Saunders International Edition. Holt-Saunders, New York, New York, USA.

Oliver, T. H., S. Gillings, M. Girardello, G. Rapacciuolo, T. M. Brereton, G. M. Siriwardena, D. B. Roy, R. Pywell, and R. J. Fuller. 2012. Population density but not stability can be predicted from species distribution models. Journal of Applied Ecology 49:581-590.

Omkar, S. S., and G. Mishra. 2010. Multiple matings affect the reproductive performance of the aphidophagous ladybird beetle, Coelophora saucia (Coleoptera: Coccinellidae). European Journal of Entomology 107:177-182.

Parker, I. M., D. Simberloff, W. Lonsdale, K. Goodell, M. Wonham, P. Kareiva, M. Williamson, B. Von Holle, P. Moyle, and J. Byers. 1999. Impact: toward a framework for understanding the ecological effects of invaders. Biological Invasions 1:3-19.

Paynter, Q., S. V. Fowler, and R. Groenteman. 2018. Making weed biological control predictable, safer and more effective: perspectives from New Zealand. BioControl 63:427-436.

Quiroz, S., C. L. Cespedes, J. B. Alderete, and J. Alarcon. 2015. Ceanothane and oleanane-type triterpenes from Talguenea quinquenervia have insecticidal activity against Cydia pomonella, Tenebrio molitor and Drosophila melanogaster. Industrial Crops and Products 74:759-766.

R Core Team 2018. R: a language and environment for statistical computing. R Foundation for Statistical Computing, Vienna, Austria. https://www.R-project.org/

Rand, T. A., C. E. Richmond, and E. T. Dougherty. 2017. Using matrix population models to inform biological control management of the wheat stem sawfly, Cephus cinctus. Biological Control 109:27-36.

Reznik, S. Y. 2009. Factors determining geographic ranges and population densities of common ragweed Ambrosia artemisiifolia L.(Asteraceae) and ragweed leaf beetle Zygogramma suturalis F.(Coleoptera, Chrysomelidae). Plant Protection News (St. Petersburg) 2:20-28. [In Russian.]

Robertson, M. P., D. J. Kriticos, and C. Zachariades. 2008. Climate matching techniques to narrow the search for biological control agents. Biological Control 46:442-452.

Roltsch, W. J., F. G. Zalom, A. J. Strawn, J. F. Strand, and M. J. Pitcairn. 1999. Evaluation of several degree-day estimation methods in California climates. International Journal of Biometeorology 42:169-176.

Sabelis, M. W. 1985. Development, chapter 2.1.2.2. Spider mites. Pages 4353 in W. Helle and M. W. Sabelis, editors. Their biology, natural enemies and control. Volume 1B. Elsevier, Amsterdam, The Netherlands.

Schaber, B., E. Balsbaugh, and B. Kantack. 1975. Biology of the flea beetle, Altica carduorum [Col.: Chrysomelidae] on Canada thistle (Cirsium arvense) in South Dakota. Entomophaga 20:325-335.

Schausberger, P. 1998. The influence of relative humidity on egg hatch in Euseius filandicus, Typhlodromus pyri and Kampimodromus aberrans (Acari, Phytoseiidae). Journal of Applied Entomology 122:497-500.

Schwarzländer, M., H. L. Hinz, R. Winston, and M. Day. 2018. Biological control of weeds: an analysis of introductions, rates of establishment and estimates of success, worldwide. BioControl 63:1-13.

Sheppard, A., R. Shaw, and R. Sforza. 2006. Top 20 environmental weeds for classical biological control in Europe: a review of opportunities, regulations and other barriers to adoption. Weed Research 46:93-117.

Simelane, D. O. 2007. Influence of temperature, photoperiod and humidity on oviposition and egg hatch of the rootfeeding flea beetle Longitarsus bethae (Chrysomelidae: Alticinae), a natural enemy of the weed Lantana camara (Verbenaceae). Bulletin of Entomological Research 97:111116.

Smith, M., L. Cecchi, C. A. Skjøth, G. Karrer, and B. Šikoparija. 2013. Common ragweed: a threat to environmental health in Europe. Environment International 61:115-126.

Sun, Y., O. Brönnimann, G. K. Roderick, A. Poltavsky, S. T. Lommen, and H. Müller-Schärer. 2017. Climatic suitability ranking of biological control candidates: a biogeographic approach for ragweed management in Europe. Ecosphere 8: e01731.

Sun, Y., Z. Zhou, R. Wang, and H. Müller-Schärer. 2018. Biological control opportunities of ragweed are predicted to decrease with climate change in East Asia. Biodiversity Science 25:1285-1294.

Thuiller, W., T. Münkemüller, K. H. Schiffers, D. Georges, S. Dullinger, V. M. Eckhart, T. C. Jr Edwards, D. Gravel, G. Kunstler, and C. Merow. 2014. Does probability of occurrence relate to population dynamics? Ecography 37:11551166.

Trethowan, P., M. P. Robertson, and A. McConnachie. 2011. Ecological niche modelling of an invasive alien plant and its 
potential biological control agents. South African Journal of Botany 77:137-146.

Van der Putten, W. H., M. Macel, and M. E. Visser. 2010. Predicting species distribution and abundance responses to climate change: Why it is essential to include biotic interactions across trophic levels. Philosophical Transactions of the Royal Society B 365:2025-2034.

Venette, R. C., editor. 2015. Pest risk modelling and mapping for invasive alien species. CABI, Wallingford, UK.

Vilà, M., J. L. Espinar, M. Hejda, P. E. Hulme, V. Jarošík, J. L. Maron, J. Pergl, U. Schaffner, Y. Sun, and P. Pyšek. 2011. Ecological impacts of invasive alien plants: a meta-analysis of their effects on species, communities and ecosystems. Ecology Letters 14:702-708.

Vinatier, F., P. Tixier, P. F. Duyck, and F. Lescourret. 2011. Factors and mechanisms explaining spatial heterogeneity: a review of methods for insect populations. Methods in Ecology and Evolution 2:11-22.

Wigglesworth, V. B. 2012. The principles of insect physiology. Springer Science \& Business Media, Berlin, Germany.

Winston, R. L., M. Schwarzländer, H. L. Hinz, M. D. Day, M. J. Cock, and M. H. Julien. 2014. Biological control of weeds: A world catalogue of agents and their target weeds. Fifth edition. USDA Forest Service, Forest Health Technology Enterprise Team, Morgantown, West Virginia, USA.

Yamanaka, T., K. Tanaka, A. Otuka, and O. N. Bjørnstad. 2007. Detecting spatial interactions in the ragweed (Ambrosia artemissifolia L.) and the ragweed beetle (Ophraella communa LeSage) populations. Ecological Research 22:185.

Yamazaki, K., C. Imai, and Y. Natuhara. 2000. Rapid population growth and food-plant exploitation pattern in an exotic leaf beetle, Ophraella communa LeSage (Coleoptera: Chrysomelidae), in western Japan. Applied Entomology and Zoology 35:215-223.
Zalucki, M. P., and R. D. Van Klinken. 2006. Predicting population dynamics of weed biological control agents: science or gazing into crystal balls? Austral Entomology 45:331-344.

Zeng, Q., Y. Zhang, G. Sun, H. Duo, L. Wen, and G. Lei. 2015. Using species distribution model to estimate the wintering population size of the endangered scaly-sided Merganser in China. PLoS ONE 10:e0117307.

Zhou, Z., J. Guo, and F. Wan, editors. 2009. Biological control of Ambrosia artemisiifolia with Epiblema strenuana and Ophraella communa. Pages 253-258 in Research on biological invasions in China. Science Press, Beijing, China.

Zhou, Z.-S., J.-Y. Guo, H.-S. Chen, and F.-H. Wan. $2010 a$. Effect of humidity on the development and fecundity of Ophraella communa (Coleoptera: Chrysomelidae). BioControl 55:313-319.

Zhou, Z.-S., J.-Y. Guo, H.-S. Chen, and F.-H. Wan. $2010 b$. Effects of temperature on survival, development, longevity, and fecundity of Ophraella communa (Coleoptera: Chrysomelidae), a potential biological control agent against Ambrosia artemisiifolia (Asterales: Asteraceae). Environmental Entomology 39:1021-1027.

Zhou, Z.-S., S. Rasmann, M. Li, J.-Y. Guo, H.-S. Chen, and F.H. Wan. 2013. Cold temperatures increase cold hardiness in the next generation Ophraella communa beetles. PLoS ONE 8:e74760.

Zhou, Z.-S., H.-S. Chen, X.-W. Zheng, J.-Y. Guo, W. Guo, M. Li, M. Luo, and F.-H. Wan. 2014. Control of the invasive weed Ambrosia artemisiifolia with Ophraella communa and Epiblema strenuana. Biocontrol Science and Technology 24:950-964.

Zhu, D. H., J. Zhu, Z. P. Peng, and F. H. Wan. 2012. Effects of photoperiod and temperature on reproductive diapause in Ophraella communa (Coleoptera: Chrysomelidae), a potential biocontrol agent against Ambrosia artemisiifolia. Insect Science 19:286-294.

\section{SUPPORTING INFORMATION}

Additional supporting information may be found online

\section{Data Availability}

Data are available from the Dryad Digital Repository: https://doi.org/10.5061/dryad.hs0r9c4 